\title{
Towards a Reinterpretation of the So-called Brazilian Neo-classical Architecture
}

\author{
ALBERTO J. SOUSA \\ Federal University of Paraiba \\ Brazil
}

Brazilian architectural historians have identified in Brazilian architecture a style of classicist nature, adopted during the period ranging broadly from 1810 , which has been regarded as the Brazilian version of European Neo-classicism - and therefore has been named Neo-classical - and as a language derived mainly from French models.

The have said, at the same time, that the French architect Grandjean de Montigny (who lived in Rio de Janeiro from 1816 until his death in 1850) was the main propagator of that style and also the most prominent of the designers who made use of it.

A careful research that I undertook during more than two years led me to an understanding which differs from these views.

\section{CLASSIFICATION AND TERMINOLOGY}

In my opinion the period which has been traditionally considered the Neo-classical era in Brazil (starting with the establishment of the Portuguese Court in Rio de Janeiro and lasting roughly until the end of the Brazilian monarchy) is not a homogeneous one, and comprises in reality two different phases which should be individualised and are separated approximately by the mid-1830s. The first one is represented by a very small number of innovative projects, concentrated in the two major cities of the country (Rio and Salvador), and characterised by the effort to adapt some European Neoclassical formulae from varied sources to the particular conditions (taste, traditions, resources, etc) of the Brazilian architectural context, still entirely dominated by solutions of colonial origin. The other was much longer and more important and was marked by the development of a peculiar Brazilian interpretation of the classical language, resulting from the fusion of national building traditions and foreign influences, which spread widely through the country and became the predominant national style.

I admit that it is acceptable to term the first period Neoclassical, as it coincided with the last decades of the age of Neo-classicism and was characterised by the attempt to introduce the Neo-classical idiom in Brazil, but because of the heterogeneity of its projects and the hesitations and the hybrid characteristics of most of them, I find that the expression Classicism of Transition is a much more meaningful way of identifying it.

The principal building of this phase, the Merchants' Exchange, at Salvador, blends Portuguese and British influences and incorporates neo-classical features that give it a singular personality. Designed by a Portuguese, Cosme Fidie, it was erected in 1813-16.

Another major project of the period, St. John Theatre (1813), at Rio de Janeiro, exhibited a different type of classicism, rooted in Portuguese Plain Architecture and distinct from international Neo-classicism. It was reminiscent of one of the best Portuguese Neo-classical buildings St. Charles Theatre, at Lisbon (1792).

French classicist influences were introduced by two French architects, Grandjean de Montigny and P. J. Pezerat, always combined with traditional colonial features - so that none of their buildings can be considered either French or Neo-classical. The former designed the Imperial Academy of Fine Arts, in 1816, and the Merchants' Exchange, in 1819, both at Rio de Janeiro. The latter, who was the private architect of the Emperor between 1825 and 1831, made plans for the Military Academy, the Imperial Residence and a house of the Emperor's mistress - all at Rio de Janeiro.

These projects and others of lesser importance showed the Brazilian ways of modernising the outdated colonial appearance of their architecture through the use of the classical idiom, then prevailing once again in the most advanced countries.

It was also during the period in question that Brazil began to prepare architects, who received a classicist training, and military engineers, who tended to adopt classicism as well but treating it in a very simplified way, compatible with the customary utilitarian concerns of their profession. Being more numerous than the academic architects and being sent to various parts of the country, the latter diffused widely their restrained interpretation of the classical language, making it the dominating tendency.

Another group of designers who contributed to direct Brazilian architecture to classicism is that represented by the Portuguese architects and engineers who came to Brazil after 
the establishment of the Portuguese Court in Rio de Janeiro, in 1808 .

During the 1810 s and 1820 s the diverse factors and influences pointed out here interacted and such a process resulted in the development of an original Brazilian version of the classical idiom, which began to appear in buildings erected in the 1830 s and characterised a new phase of Brazilian architecture.

Such a Brazilian interpretation of classicism reached its maturity in the $1840 \mathrm{~s}$, thanks to the erection of some remarkable projects which established many of its basic characteristics, and in the following years spread gradually through the country, becoming the prevailing style û which was used, from its emergence, for more than half a century. It has been incorrectly named Neo-classical by Brazilian architectural historians.

I have proposed the term Brazilian Imperial Classicism to identify such a style. It indicates the basic nature of the idiom and points out the period in which it was used (the imperial era of Brazil), which distinguishes it from the subsequent Academic Classicism of the first republican decades (that is to say, from the late 1880 s onwards).

The main reason why it should not be named Neoclassicism is the sharp distinction between its stylistic characteristics and those of that language.

Unlike the latter, it was not marked by such important basic features as a monumental and archaelogical character and the revival of ancient Greek architecture.

Usual and essential components of Neo-classical vocabulary - like pedimented porticos with colossal columns occupying the centre of the facades, rows of detached or engaged columns, temple-like fronts, rusticated ground floors and low domes recalling that of the Roman Pantheon - are an exception or do not appear in Brazilian Imperial Classicism. And the same comment applies to other tendencies presented by some Neo-classical buildings, like that of exhibiting a weighty appearance and a strong predominance of solid over void on the facades.

Furthermore, besides having distinct appearances, the buildings of Brazilian Imperial Classicism and those of Neoclassicism were constructed in different periods, the latter in the second half of the 18 th century and in the first decades of the following century - the bulk of the production of Brazilian Imperial Classicism lying thus outside the conventional Neo-classical era.

It should be added that the kind of thinking that governed European Neo-classicism was not the same that guided Brazilian Imperial Classicism.

Considering that this style drew inspiration from Italian Renaissance and was contemporary with Renaissance Revival, which was introduced by the British in the 1830s and was subsequently adopted in other countries, one could be tempted to regard it as a possible Brazilian version of that revival - which would be another wrong interpretation. While projects of the Renaissance Revival tended usually to reproduce quite faithfully specimens of Italian palazzi and villas, Brazilian Imperial Classicism combined Renaissance formulae - often reinterpreted - with other influences, generating a distinct type of classicist architecture. Nevertheless, Brazil had the opportunity to know the language of Renaissance Revival through certain buildings affiliated to it erected in places like Rio de Janeiro - such as Catete Palace (1860s), conceived by a German architect (Waeneldt).

\section{SOURCES OF THE STYLE}

The idea of finding that the architecture I am calling Brazilian Imperial Classicism derived from French models is still more injustifiable than that of terming it Neo-classical. Probably it stemmed from the mistake in thinking that the style in question owes its development and diffusion to the French architect Grandjean de Montigny, who would be the origin of the French character it is supposed to have. It is likely also that the supporters of such an idea judged that a good indication it was right was the fact that the main countries of Spanish America sought inspiration in French architecture after their independence (Brazil would have thus followed a dominant tendency of Latin America), a rather defective judgment, as Brazilian history in the first decades before and after independence differs sharply from that of those countries.

None of the major characteristics of Brazilian Imperial Classicism has its source in French Classicism or Neoclassicism (typically French motifs, like mansards and square domes, would appear in Brazil only is subsequent classical languages). Even those which seem at a first glance to have been borrowed from French buildings have in reality an Italian origin. Considering this and the fact that the buildings of Brazilian Imperial Classicism do not recall those of French Neo-classicism, it is amazing that the idea in question has been able to prevail until the present day.

Indeed, it was from certain types of architecture produced in Portugal and Brazil during the 17th and 18 th centuries that most of the essential characteristics of Brazilian Imperial Classicism derived.

Those which gave the idiom its basic character - sobriety, dominance of geometrical shapes, division of facades into panels separated by projecting rectilinear elements and preference for nearly flat facades without deep projections or recesses - were borrowed from the Plain Style of religious buildings, which in Brazil persisted until the second quarter of the 18th century. This peculiarly Portuguese language was also the origin of the practice of distinguishing the panels marked on the facades from their frames by making these in dressed stone (or sometimes in plaster imitating this material) and the former in plaster painted white.

Other important features, concerning mainly the colours and materials of the elevations, derived from other segments of Luso-Brazilian architecture. The contrast between pink panels and white projecting linear components (pilasters, cornices, window surrounds etc.) was found in many Portuguese projects of the 18th century. The use of azulejos 
(square glazed ceramic tiles) to cover the panels of the facades had already been done in certain Brazilian Baroque churches and had another antecedent in a similar utilisation on internal walls of a much larger number of religious edifices of the 18th century. Many times, the dressed stone of components such as surrounds and entablatures was imported from Lisbon. In other cases, it was the massing of the buildings that followed models belonging to the LusoBrazilian heritage, like the one in which the composition was crowned by a partial floor having the front elevation on the same plane of the rest of the facade and occupying only a central portion of it.

Another major source of inspiration was the architecture of certain buildings of Italian Renaissance, which provided both principles of composition and models of architectural features - such as the practice of concealing roofs with parapets, the use of horizontal projecting components to separate the floors on the facades, the repetition of identical openings, triangular pediments marking the centre of the main elevations, balustrades, statues and urns adorning parapets and rectangular openings topped with cornices. It should be noted that Italian influences were present in the Portuguese Plain Style and were indirectly assimilated when Brazilian Imperial Classicism borrowed elements from that idiom.

French and British influences appeared only in a limited number of projects, usually playing a minor role in the composition, so that it can be said that Brazilian Imperial Classicism resulted basically from the fusion of characteristics derived from the Luso-Brazilian architectural heritage and the Italian Renaissance.

\section{CHARACTERISTICS OF THE STYLE}

Brazilian Imperial Classicism was used mainly - and widely - in residential and public buildings. In spite of certain common features, it was markedly distinct from the style of the buildings of the same nature built during the colonial era û that was different from that of the religious architecture from which it drew inspiration.

In the latter buildings, the composition was dominated by the roof and was not crowned by a triangular pediment. Often the only vertical structural members appearing on the facades were plain pilasters acting as quoins, which sometimes were omitted. Usually the openings were rectangular, without cornices, or segmental-arched.

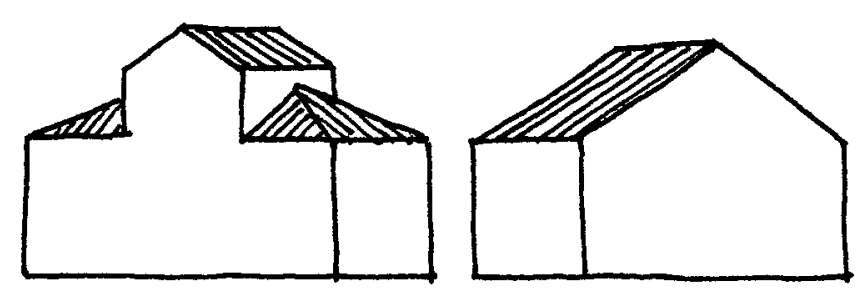

Fig. 1. Two types of colonial massing used in Brazilian Imperial Classicism.
In Brazilian Imperial Classicism, hipped roofs were surrounded by parapets that made them a minor architectural feature. In gabled roofs, eaves were hidden by parapets as well and the sloping edges were finished with copings that projected slighted inwards on the tiles, the roof looking thus almost framed; this diminished its importance in the composition, which was dominated by the classical triangular pediment normally marked on the gabled wall, often very prominent as frequently that wall was much longer than the rectangular ones. Parapets commonly took the form of solid walls, but balustrades were sometimes used. For the facades, a fundamental design principle was dividing them into rectangular panels framed by projecting rectilinear features, such as pilasters, entablatures, cornices and string courses. Often each panel corresponded to a storey, but sometimes it encompassed more than one floor in which case it contained only one opening per floor. Commonly, a panel of a different shape û a triangle û was added to the main elevations, in the form of sober pediments which could be simply decorative (forming part of parapets) or be the finish of the upper part of a gabled wall. The classical components employed to delimitate the panels had mostly a geometrical appearance (pilasters being of the Tuscan order, entablatures being simplified, cornices being plain, etc.), the consequence of this being that columns appeared very rarely on the facades, almost always without playing a major role in the composition. Each panel contained a set of identical openings separated by equal intervals (or simply one or two openings), their preferred model being the rectangular one topped with cornice and the round-arched one with archivolt; the openings were bordered by slightly projecting surrounds that emphasised their geometrical shape. Other mouldings of geometrical aspect were sometimes incorporated into the facades, both on parapets (quite often and with various configurations) and on the panels (string courses and the line formed of archivolts and segments of horizontal bands connecting them). Without deep projections and recesses, like columns, projecting entablatures, niches and sculpted reliefs, the surfaces of the facades looked in general almost flat, which gave the massing a nearly geometrical appearance.

Brazilian Imperial Classicism was thus a language dominated by geometry, this fact together with some characteristics mentioned above making it clearly distinct from the classicist architectures produced in Europe in its time and during the preceding decades subsequent to the mid-18th century. Although restrained and geometrical it was not a sort of stripped classicism, as it was not concerned with avoiding the use of conventional classical features and utilising instead plain reinterpretations of these; it employed some of these features, but only those which presented naturally a geometrical aspect (like Tuscan pilasters) or could acquire it through their simplification (like Ionic entablatures). In other words, it was a peculiar type of classicism based on the use of geometric shapes and selected severe classical forms. 


\section{FIVE SELECTED PROJECTS}

The nature and the characteristics of Brazilian Imperial Classicism can be better understood through the examination of the external composition of some of its buildings. I have selected five projects of varied types which are outstanding, for their architectural quality, and constitute a fairly representative sample of the style in question.

Imperial Palace at Petropolis (near Rio de Janeiro). Designed by Guillobel, a Portuguese-born architect and engineer, this building was begun in the early 1840 s. Its massing is a modified version of the traditional LusoBrazilian formula in which the central part of the main elevation had an additional floor. The materials and the colour treatment of the facades were also borrowed from Portuguese traditions (painted plaster and stone, and the contrast between pink panels and white pilasters, cornices and surrounds. The portico topped by a balcony was inspired by a similar feature existing in theatres of Brazil and Portugal - which was reminiscent of the one appearing in the famous La Scala, at Milan. The principle of dividing the facades into panels found here a perfect demonstration, each opening corresponding to a panel. Being an imperial house, some decorated classical motifs - such as Corinthian capitals were incorporated into the facades, without altering their geometrical character.

Pedro II Asylum, at Rio de Janeiro. It was erected between 1842 and 1852 , and its facade has been attributed to Jacinto Rabelo, a Brazilian architect trained at the Academy of Fine Arts, at Rio de Janeiro. Except for the balconies, the upper floor has a design similar to that of the ground floor of the preceding building. However, the ground floor received a rather different treatment: its panels are much larger (the pilasters that separate them are not shown in the photograph), contain several windows and do not feature any classical

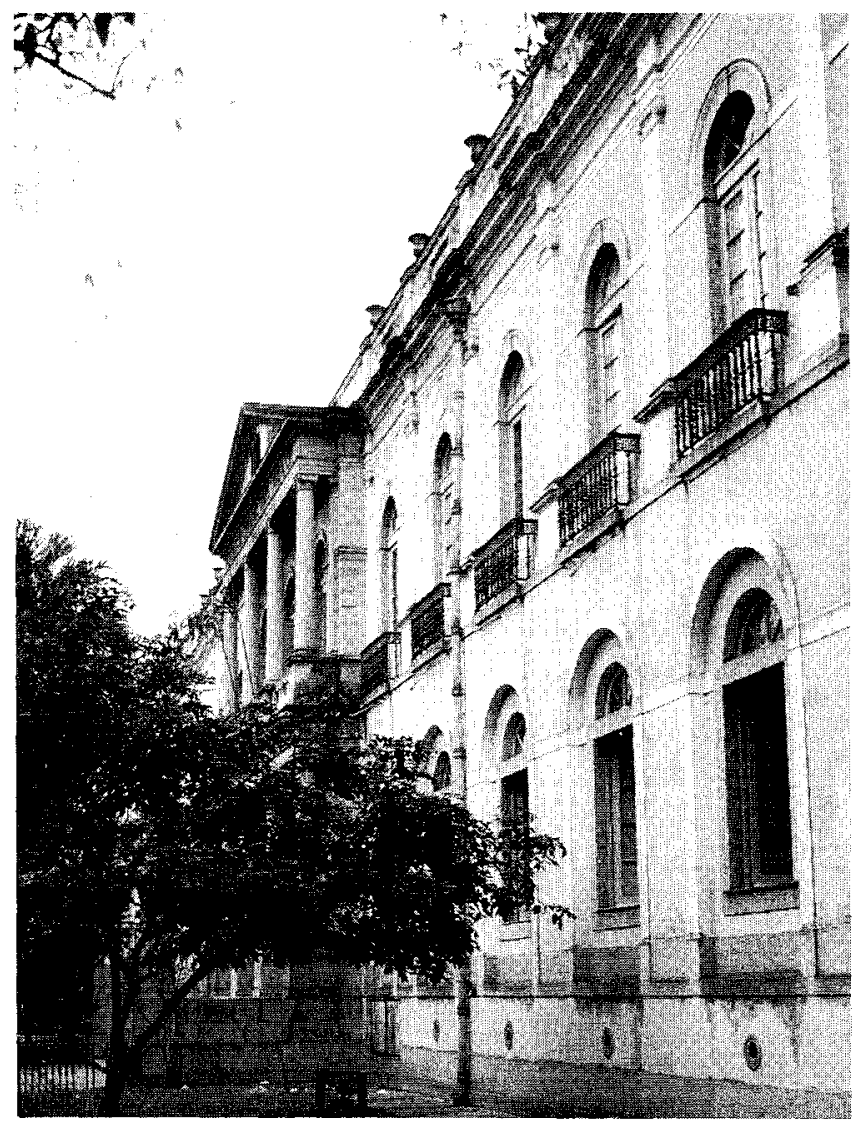

Fig. 3. Pedro II Asylum, at Rio de Janeiro.

motif, the composition being strictly geometrical, consisting of a regular arrangement of rectangular and semicircular plain frames. The pedimented central portico, in dressed stone, with two tiers of columns, is reminiscent of Italian Renaissance and represents one of the few examples appear-

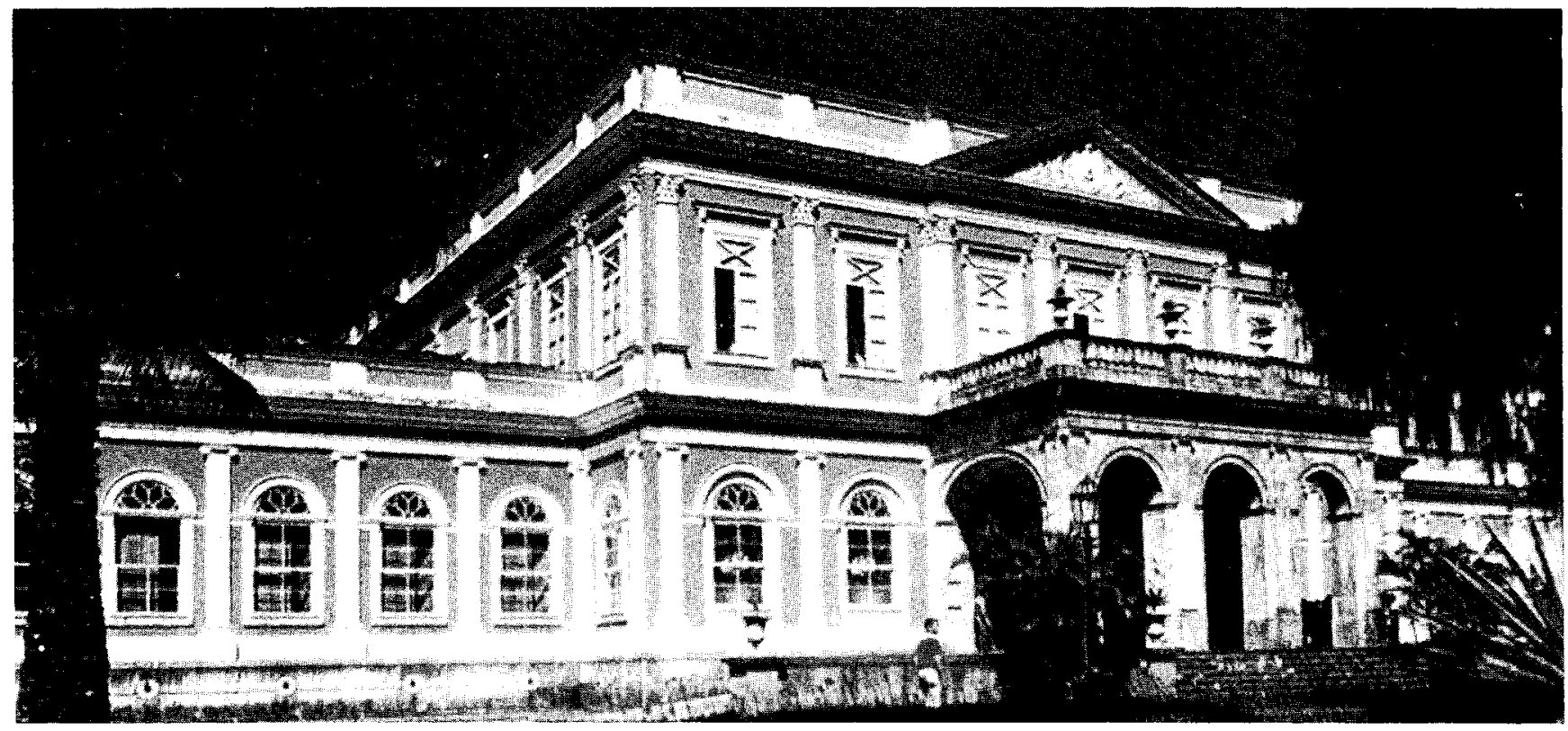

Fig. 2 Imperial Palace, at Petropolis. 
ing in buildings of Brazilian Imperial Classicism. The panels are pink and in plaster, and the linear projecting components are either in dressed stone or in plaster painted white.

Pernambuco's Secondary School, at Recife. Conceived by Mamede Ferreira, a brilliant Brazilian engineer trained in Portugal and France, it was built in 1855-66. Its facade, in plaster, is composed almost entirely of geometrical forms, rationally arranged, the only noticeable exception being a classical central doorway in stone, inspired probably by British Georgian architecture. The focus of the composition is a blank triangular pediment incorporated into the parapet, which contrast with the other pink panels, of rectangular shape, that contain white lines generated by mouldings. Another contrast on which the design is based is the one between the monotonous repetition of identical openings and the varied sizes and proportions of the rectangular panels. A very prominent feature is the continuos line formed of archivolts and horizontal bands, that gives movement and character to the facade.

Rodrigues Mendes House. Built circa 1870, this superb suburban house is the work of an unknown designer. Two of its fundamental characteristics were borrowed from local colonial traditions, which give it an unmistakable Brazilian character: the massing, having a partial upper floor in its central part, and the azulejos that clad the panels of the main facades. The building draws its beauty mainly from its dramatic massing that resulted from the articulation of the mentioned colonial formula with a projecting central volume in the form of a portico topped with a balcony. While this portico is divided into vertical panels separated by Tuscan pilasters, the two volumes that flank it are divided by a series of horizontal lines which constitute a major geometrical feature of their facades - whose appearance is not fully geometrical simply by reason of the projecting imposts that were marked in the surrounds of the windows. Geometry

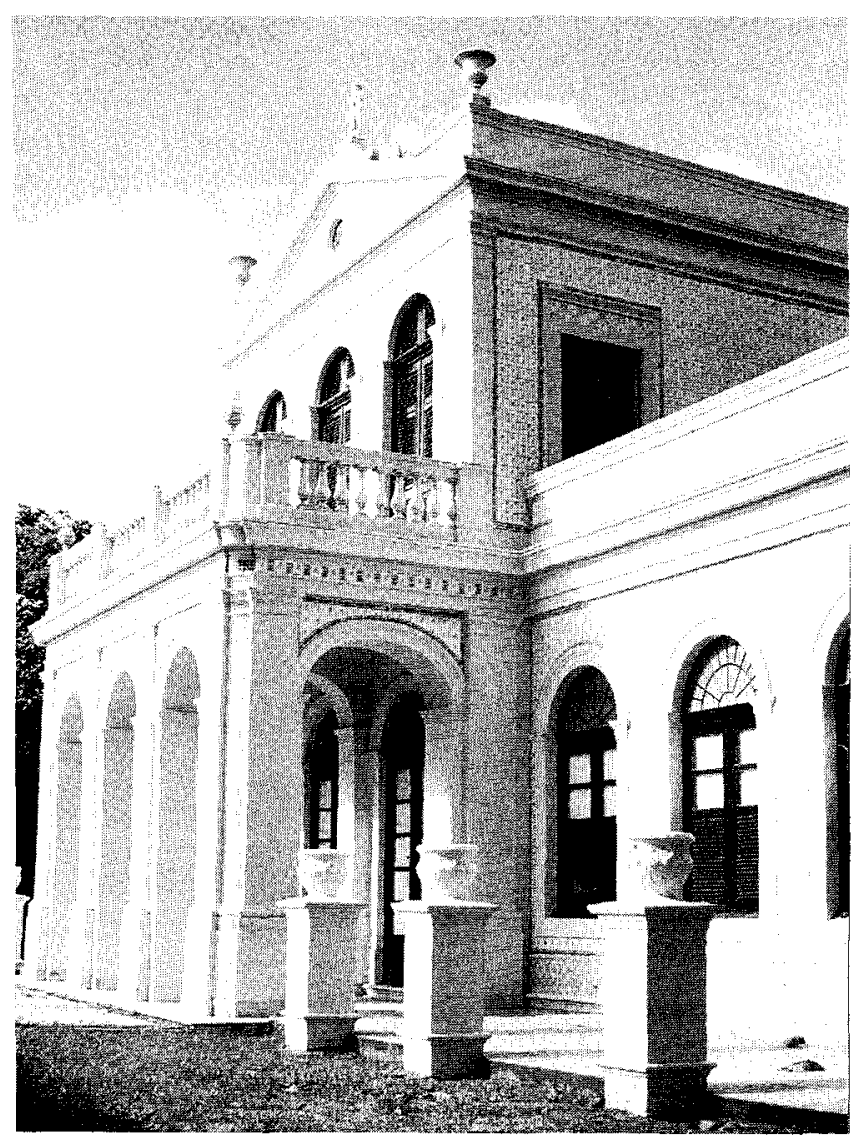

Fig.5. Rodrigues Mendes House, at Recife.

plays also an important role in the upper floor, dominating its side facades. But it is the combination of its shapes with ornamented components that gives the composition its character.

Baron of Aracati House, at Aracati (Ceara). This building is a good example of urban house occupying a corner of

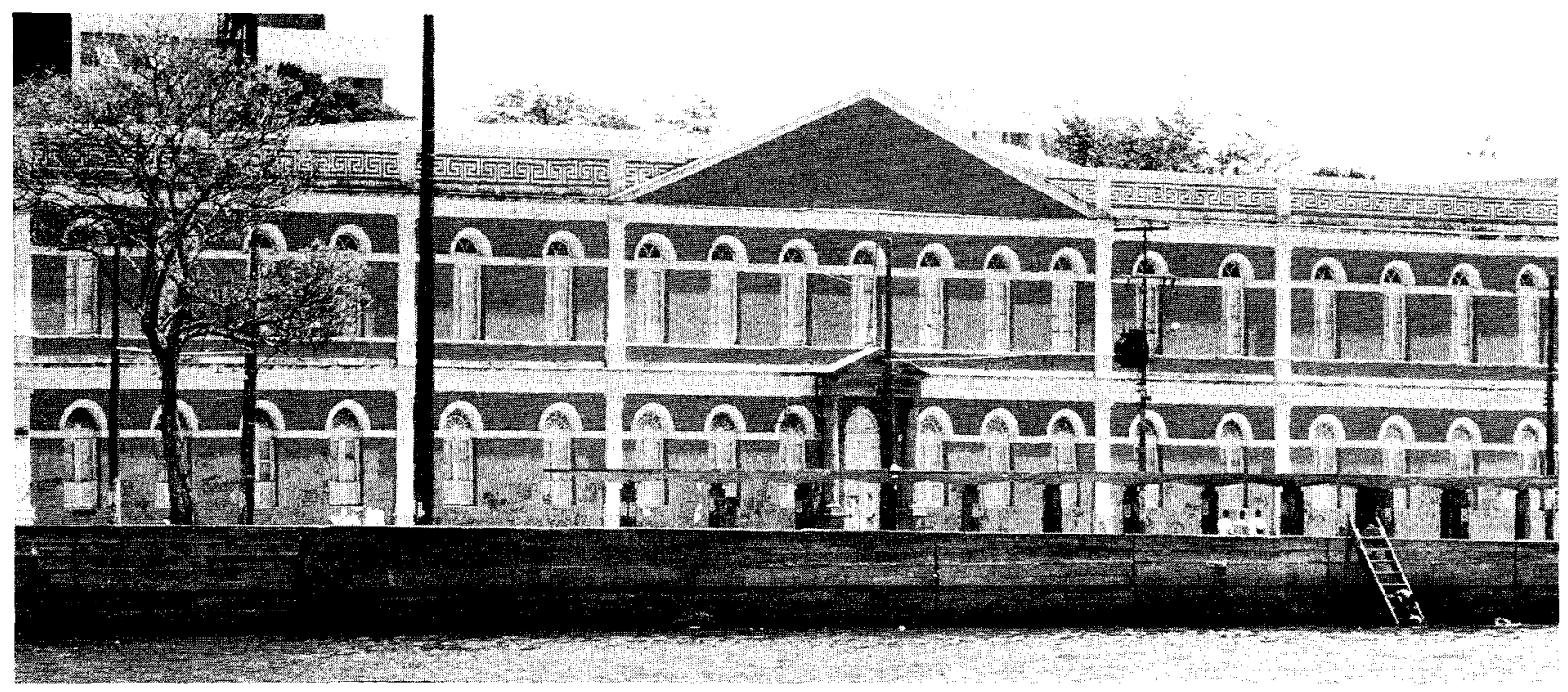

Fig. 4. Pernambuco's Secondary School, at Recife. 


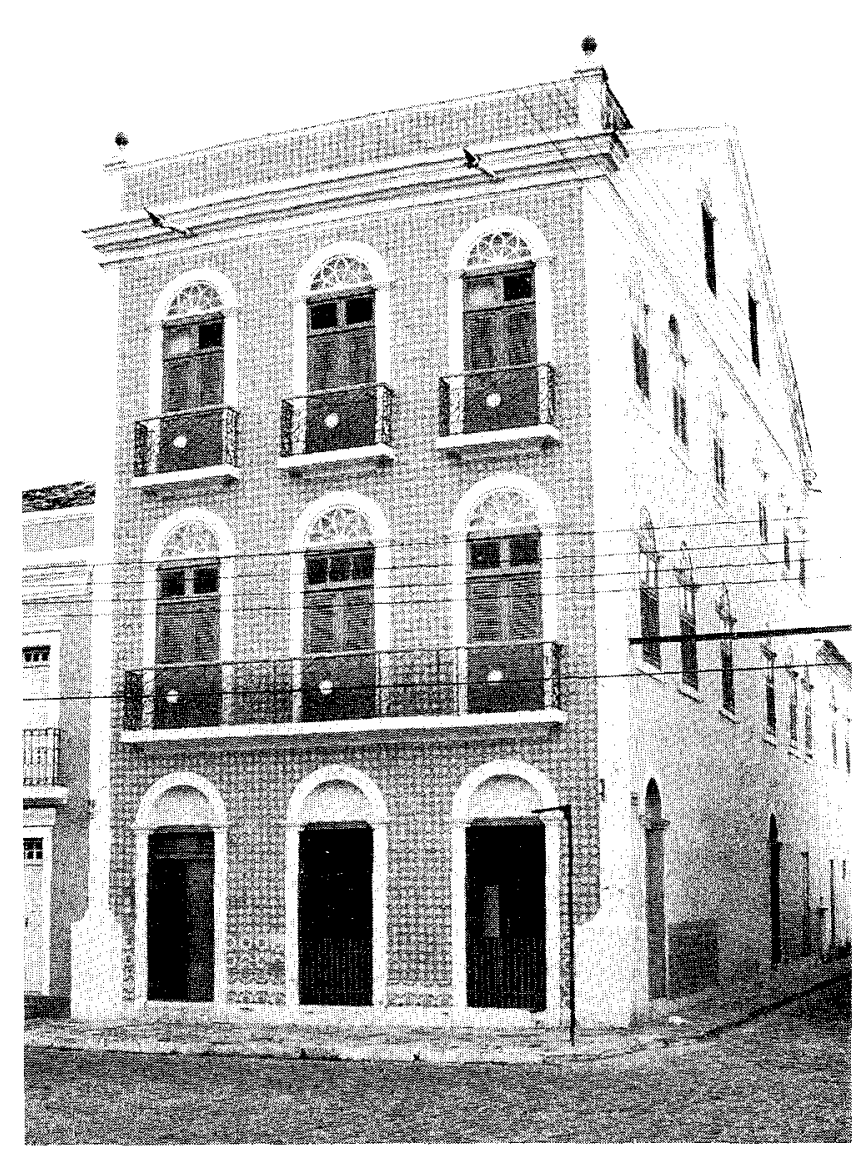

Fig. 6. Baron of Aracati House, at Aracati.

a block. Among the characteristics that determine its appearance, three are of colonial origin: the massing (featuring a long gabled lateral facade and a narrow rectangular front elevation), the bright yellow azulejos that cover the latter, and the fact that in this all the openings are placed in a single panel encompassing all the storeys. The classicist character of the composition derives mainly from the regular repetition of identical round-arched openings, the framed solid parapet, the broad triangular pediment marked on the gabled wall and the framing of the main facade by two corner pilasters, a simplified entablature and a cornice. Geometry dominates both facades, but is attenuated by the projecting imposts of the surrounds.

\section{MONTIGNY'S CONTRIBUTION}

The view that the French architect Grandjean de Montigny was the father, the propagator and the main designer of the so-called Brazilian Neo-classicism is one of those magic ideas that succeed in prevailing during a long period in spite of being untrue. Its fragility is easily revealed by a more careful analysis.

As some important buildings that employed the Neoclassical idiom existed already in Brazil when he arrived in Rio de Janeiro, it has been said that it was he who introduced pure Neo-classicism in the country. But in reality none of his buildings was genuinely Neo-classical; they were more related to Italian Renaissance and incorporated traditional Luso-Brazilian features that contributed significantly to the definition of their appearance.

On the other hand, his performance as a practising architect was in fact relatively modest, since the number of buildings he left is small in comparison with the length of his activity in Brazil (more than three decades), and none of these buildings can be considered a remarkable architectural conception. His best executed projects were those designed in the 1810 s, already mentioned here, which nevertheless cannot rival St. John Theatre, erected in Rio in the same decade. In the 1820's he was less active, the architecture of the city being then dominate by the Emperor's architect, Pezerat, another Frenchman, who later on would work in Portugal during many years. In the following decade he had to compete with Julio Koeller, a very active military engineer, but was able to get three important commissions (a new Merchants' Exchange, a market and a school), none of which resulted in a notable architectural creation. And in the 1840 's, when several large and outstanding projects began to be built, none of these was his work. Thus, he was not the author of any of the best buildings produced in Brazil during its so-called Neo-classical era (from 1810 to 1890 , roughly).

Probably he contributed more to the development of classicism in Brazil as the head of the course of architecture of the country's Academy of Fine Arts than as a practising architect. Nevertheless, it should be noted that the works of his former students represented only a small portion of the whole of the cultivated classicist architecture produced during the imperial period, the vast majority of which was designed by foreign architects and engineers and Brazilian military engineers. It should be remarked also that the individual style of his former students who became renowned architects proved clearly distinct from the one he practised.

Furthermore the influence exercised by Montigny remained virtually confined to Rio de Janeiro and the neighbouring areas, being not felt in other major centres of production of classicist architecture, like Belem and Recife, cities whose joint output was larger and more important than that of Rio de Janeiro. (Recife rivalled this city in the creation of the architecture in question, and even surpassed it in terms of the originality of the buildings produced).

Montigny's work, as both a teacher and a practitioner, was thus only one of the various factors that resulted in the birth and development of Brazilian Imperial Classicism - which included the action of European architects and engineers (from Portugal and other nations) and the contribution of Brazilian architects and engineers trained in the country or abroad. It was not an essential factor and I am convinced that without it such a style would have appeared and evolved normally. 